\title{
Discontinuous Daily Temperatures in the WATCH Forcing Datasets
}

\author{
Henning W. Rust, Tim Kruschke, Andreas Dobler, Madlen Fischer, And Uwe Ulbrich \\ Institut für Meteorologie, Freie Universität Berlin, Berlin, Germany
}

(Manuscript received 7 July 2014, in final form 30 October 2014)

\begin{abstract}
The Water and Global Change (WATCH) forcing datasets have been created to support the use of hydrological and land surface models for the assessment of the water cycle within climate change studies. They are based on 40-yr ECMWF Re-Analysis (ERA-40) or ECMWF interim reanalysis (ERA-Interim) with temperatures (among other variables) adjusted such that their monthly means match the monthly temperature dataset from the Climatic Research Unit. To this end, daily minimum, maximum, and mean temperatures within one calendar month have been subjected to a correction involving monthly means of the respective month. As these corrections can be largely different for adjacent months, this procedure potentially leads to implausible differences in daily temperatures across the boundaries of calendar months. We analyze day-to-day temperature fluctuations within and across months and find that across-months differences are significantly larger, mostly in the tropics and frigid zones. Average across-months differences in daily mean temperature are typically between $10 \%$ and $40 \%$ larger than their corresponding within-months average temperature differences. However, regions with differences up to $200 \%$ can be found in tropical Africa. Particularly in regions where snowmelt is a relevant player for hydrology, a few degrees Celsius difference can be decisive for triggering this process. Daily maximum and minimum temperatures are affected in the same regions, but in a less severe way.
\end{abstract}

\section{Introduction}

An assessment of the global water cycle requires reliable datasets with global coverage of the meteorological variables driving the water cycle. The European Union project Water and Global Change (WATCH) has created global datasets meant to meet these needs, for example, the WATCH Forcing Data Twentieth Century (WFD) and WATCH Forcing Data ECMWF interim reanalysis (ERA-Interim) (WFDEI; Weedon et al. 2010, 2011, 2014). These datasets have been frequently used in the context of hydrological modeling (e.g., Gudmundsson et al. 2011; Koch et al. 2013; Prudhomme et al. 2014).

The WFD is based on the 40-yr ECMWF Re-Analysis (ERA-40; Uppala et al. 2005) with variables adjusted by observational products, while the WFDEI uses ERA-Interim (Dee et al. 2011) as a basis. Subdaily temperatures are adjusted such that their monthly

Corresponding author address: Henning W. Rust, Institut für Meteorologie, Freie Universität Berlin, Carl-Heinrich-BeckerWeg 6-10, D-12165 Berlin, Germany.

E-mail: henning.rust@met.fu-berlin.de means match the corresponding Climatic Research Unit (CRU) dataset's monthly temperatures running from January 1958 to December 2001 (New et al. 1999, 2000; Mitchell and Jones 2005; Weedon et al. 2010, 2011). This implies the potential for very different adjustments on adjacent days belonging to different calendar months. Hence, the difference in daily temperatures between the first day of the month and the last day of the previous month might be very different from the day-to-day temperature difference within the same month. Ideally, these day-to-day differences at the beginning or end of calendar months are of the typical size of day-to-day temperature variations and hence should be neither detectable nor pose serious problems for further application of the WATCH forcing datasets in a hydrological context. But what if the typical across-months differences are notably larger than typical within-months differences? Implausible temperature differences between adjacent days occur. To quantify this problem, we compare the distribution of day-to-day differences in daily temperatures within calendar months to differences across months for both the WFD and the WFDEI. Specifically, we count events with acrossmonths daily temperature differences that are larger in 


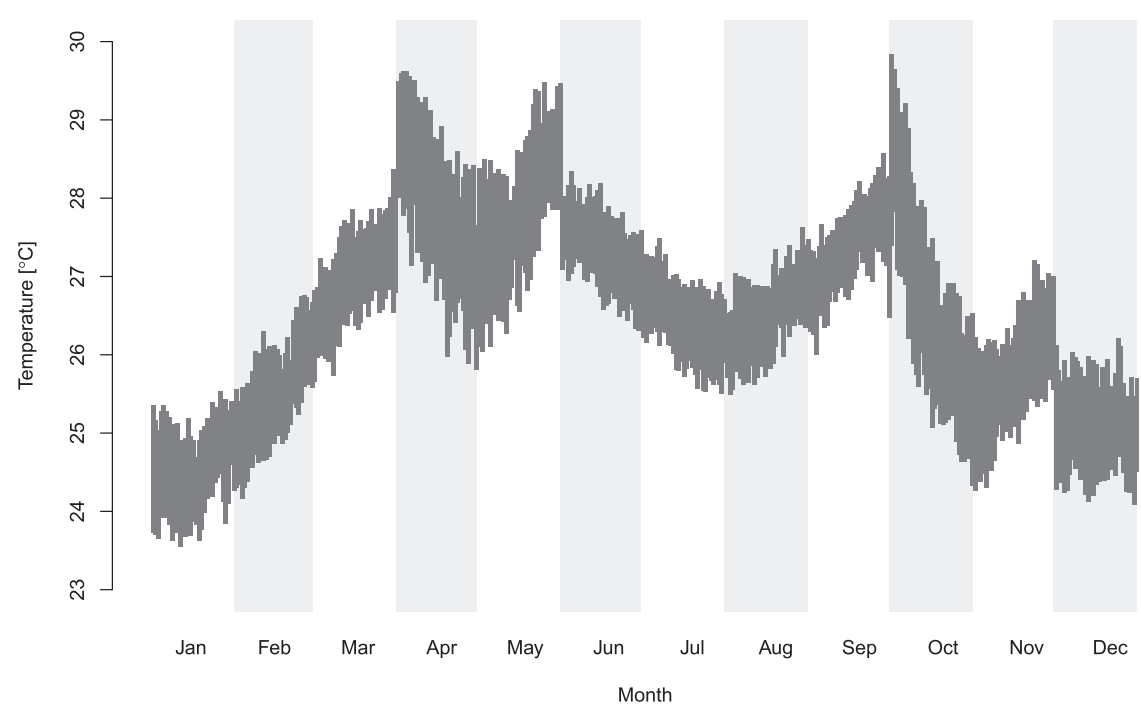

FIG. 1. IQRs of daily mean temperature from WFD for a grid box in Ethiopia $\left(11.25^{\circ} \mathrm{N}\right.$, $40.75^{\circ} \mathrm{E}$ ). The dark gray bars mark the IQR of the 45 -yr temperature series for a given day in the year. Alternating gray and white shadings separate different calendar months.

magnitude than extreme within-months daily temperature differences and compare the magnitude of acrossmonths temperature differences to the corresponding within-months differences in total and on a monthly resolved basis.

The problem of discontinuities in adjusted (bias corrected) reanalyses has been discussed in, for example, Hempel et al. (2013). Hagemann et al. (2011) and Piani et al. (2010) already pointed to potential jumps between months and suggested a continuous correction.

The WATCH forcing datasets (WFD and WFDEI) as well as the methods used to detect and quantify atypical daily temperature differences are presented in section 2 . Section 3 shows the affected regions and quantifies the resulting discontinuities for the whole datasets and for transitions from specific months to the subsequent ones; conclusions are given in section 4 .

\section{Data and methods}

We consider mean (tas), minimum (tasmin), and maximum (tasmax) near-surface air temperature $(2 \mathrm{~m})$ from the WFD and WFDEI. The data can be obtained from the International Institute for Applied Systems Analysis (ftp://rfdata:forceDATA@ftp.iiasa.ac.at).

Plotting interquartile ranges (IQRs; the range between the third and first quartiles) of daily mean temperatures across the year for a grid box from Ethiopia in WFD provides a first visual impression of the problem (Fig. 1). The larger-than-usual differences between daily temperature at the boundaries of months become particularly evident between March and April, May and
June, September and October, and November and December; these are of the size of the interquartile range of within-month temperature differences.

In the following, we compare day-to-day temperature fluctuations between days $i$ and $i-1$ :

$$
\Delta T_{i}=T_{i}-T_{i-1}
$$

and within-months fluctuations $\Delta T_{i, \text { in }}$ are compared to across-months fluctuations $\Delta T_{i \text {,across. }}$ Figure 2 shows the histograms of absolute temperature differences $\left|\Delta T_{i, \text { in }}\right|\left(N_{\text {in }}=45 \mathrm{yr}\right.$ with $365-12$ days; gray bars $)$ and $\left|\Delta T_{i, \text { across }}\right|\left(N_{\text {across }}=45 \mathrm{yr} \times 12\right.$ days; orange bars $)$, as well as the differences in their sample means (dashed lines) for the same grid box in Ethiopia used for Fig. 1. The 0.95 quantile of within-months daily fluctuations is marked as a solid vertical line, and we classify values below this line as "normal" day-to-day variations, which are expected to be exceeded in only $5 \%$ of day-to-day variations. For the given example grid box, we find that $24.5 \%$ of across-months day-to-day variations exceed this line and thus more than the expected $5 \%$. To assess whether this number of exceedances is significantly different from the expected 5\% within-months exceedances, we construct the following hypothesis test: under the null hypothesis $H_{0}$, we assume that $\left|\Delta T_{i \text {,across }}\right|$ are realizations of independent and identically distributed random variables (iid) with the same distribution as $\left|\Delta T_{i, \text { in }}\right|$. We further assume the sample estimate of the 0.95 quantile being an adequate estimate of the true quantile and, hence, a probability of $p=0.05$ for $\left|\Delta T_{i, \text { across }}\right|$ exceeding it. For $45 \mathrm{yr}$ with 12 months, we 


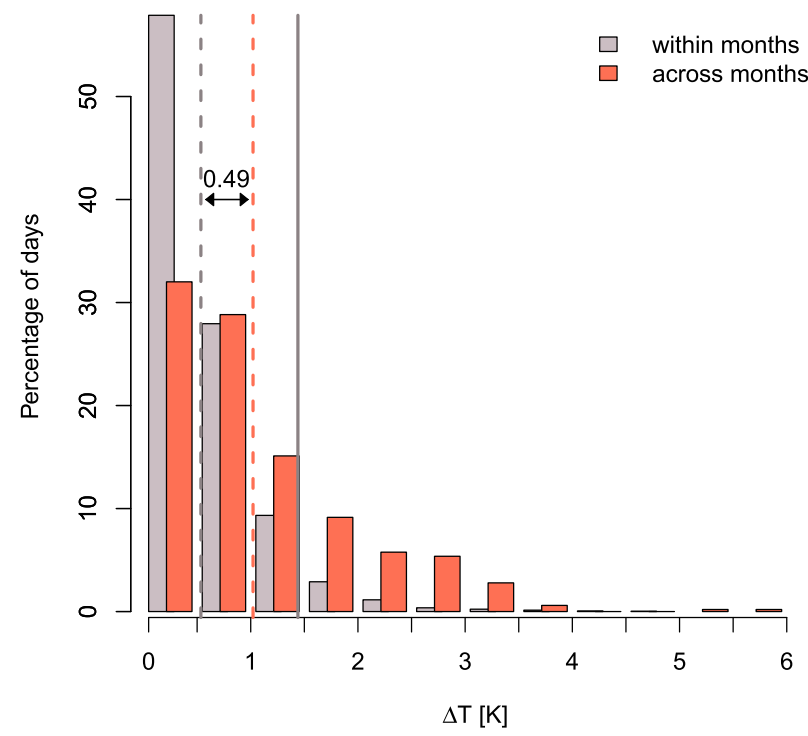

FIG. 2. Histogram of absolute daily temperature fluctuations from WFD within months $\left|\Delta T_{i, \text { in }}\right|$ (45 yr with 365 days - 12 days; gray bars) and across months $\left|\Delta T_{i \text {,across }}\right|$ ( $45 \mathrm{yr}$ with 12 days; orange bars). The dashed vertical lines mark the mean of the corresponding distributions; the solid gray line marks the 0.95 quantile of $\left|\Delta T_{i, \text { in }}\right|$.

have $N=45 \mathrm{yr} \times 12$ months $=540$ beginnings of months, that is, $N$ trials of a Bernoulli experiment with probability $p=0.05$ for exceeding this quantile. We thus expect 27 exceedances and deduce from the binomial distribution that the number of exceedances is smaller than 36 for $95 \%$ of all trials. These $36 \mathrm{ex}-$ ceedances correspond to about $7 \%$ of $N=540$ trials, and hence, $7 \%$ marks a critical value, which we consider as not being consistent with $H_{0}$ at a $5 \%$ level of significance.

Additionally, we analyze the direction of the discontinuities, that is, whether the across-month temperature differences are positive or negative on average. These average across-month temperature differences $\overline{\Delta T_{m \text {,across }}}$ are compared separately for every month $m$ to normal variations, estimated from the temperature differences before and after the transitions across months:

$\overline{\Delta T_{m, \text { in }}}=\frac{1}{2 n} \sum_{y=1}^{n}\left(T_{m, f-1, y}-T_{m, f-2, y}+T_{m, f+1, y}-T_{m, f, y}\right)$,

with the indices $(m, f, y)$ and $(m, f+1, y)$ denoting the first $f$ and second $f+1$ day of calendar month $m$ in year $y$, respectively; $f-1$ and $f-2$ are thus the last and second-to-last day of the previous month. Additionally, we consider the normalized difference in mean values of within-months and across-months fluctuations:

$$
t_{m}=\frac{\overline{\Delta T_{m, \text { across }}}-\overline{\Delta T_{m, \text { in }}}}{\sqrt{\frac{s_{\Delta T_{m, \text { across }}}^{2}}{n}+\frac{s_{\Delta T_{m, \text { in }}}^{2}}{2 n}}},
$$

with $s^{2}$ being the associated sample variances for month $m$ and $n$ the number of years available.

\section{Results}

For every grid box in WFD and WFDEI, we obtain fractions of days with absolute across-months temperature fluctuations $\left|\Delta T_{i \text {,across }}\right|$ above the estimated 0.95 quantile of absolute within-months daily fluctuations $\left|\Delta T_{i, \text { in }}\right|$. These fractions (\%) are depicted in Fig. 3 for minimum (i.e., tasmin), mean (i.e., tas), and maximum (i.e., tasmax) daily temperature. For both datasets, regions with very pronounced differences in the mean temperature (Fig. 3, middle), that is, fractions of $20 \%$ or larger, are the Horn of Africa, the southern region of the Arabian Peninsula, and Angola. Large parts of Africa, South America, Greenland, Siberia, India, and Southeast Asia are also affected, but in a less severe way. Minimum (Fig. 3, top) and maximum (Fig. 3, bottom) daily temperature show the same regional patterns, but in a less pronounced way. Additionally, Fig. 4 gives ratios of mean absolute values $\overline{\left|\Delta T_{\text {across }}\right| /\left|\Delta T_{\text {in }}\right|}$ for the daily minimum, mean, and maximum temperatures. The above-mentioned regions show ratios of 2 or more, indicating that the average across-months fluctuation is of twice the magnitude than the average within-months fluctuation. Corresponding results for minimum (Fig. 4, top) and maximum (Fig. 4, bottom) daily temperatures again show basically the same spatial patterns. The differences of across-months versus within-months magnitude is, however, not as pronounced as for daily mean temperatures. Day-to-day fluctuations of extreme temperatures are generally larger (more variable) than those of mean temperatures, and thus the adjustment does not lead to outstanding across-months fluctuations that easily. Regions that are somewhat affected or not affected (i.e., a fraction of less than 7\%) roughly correspond to areas where the CRU temperature dataset profits from a particularly good coverage of observational data (see Mitchell and Jones 2005).

To resolve seasonal effects, Fig. 5 shows normalized differences [Eq. (3)] of across-months and surrounding within-months temperature fluctuations for every transition from one month to the next for WFD. The color bar is chosen such that color starts for $\left|t_{m}\right|>2$, which roughly corresponds to a two-sided $t$ test on a $95 \%$ level of significance (Welch's $t$ test with modified degrees of freedom; e.g., von Storch and Zwiers 1999). A positive 

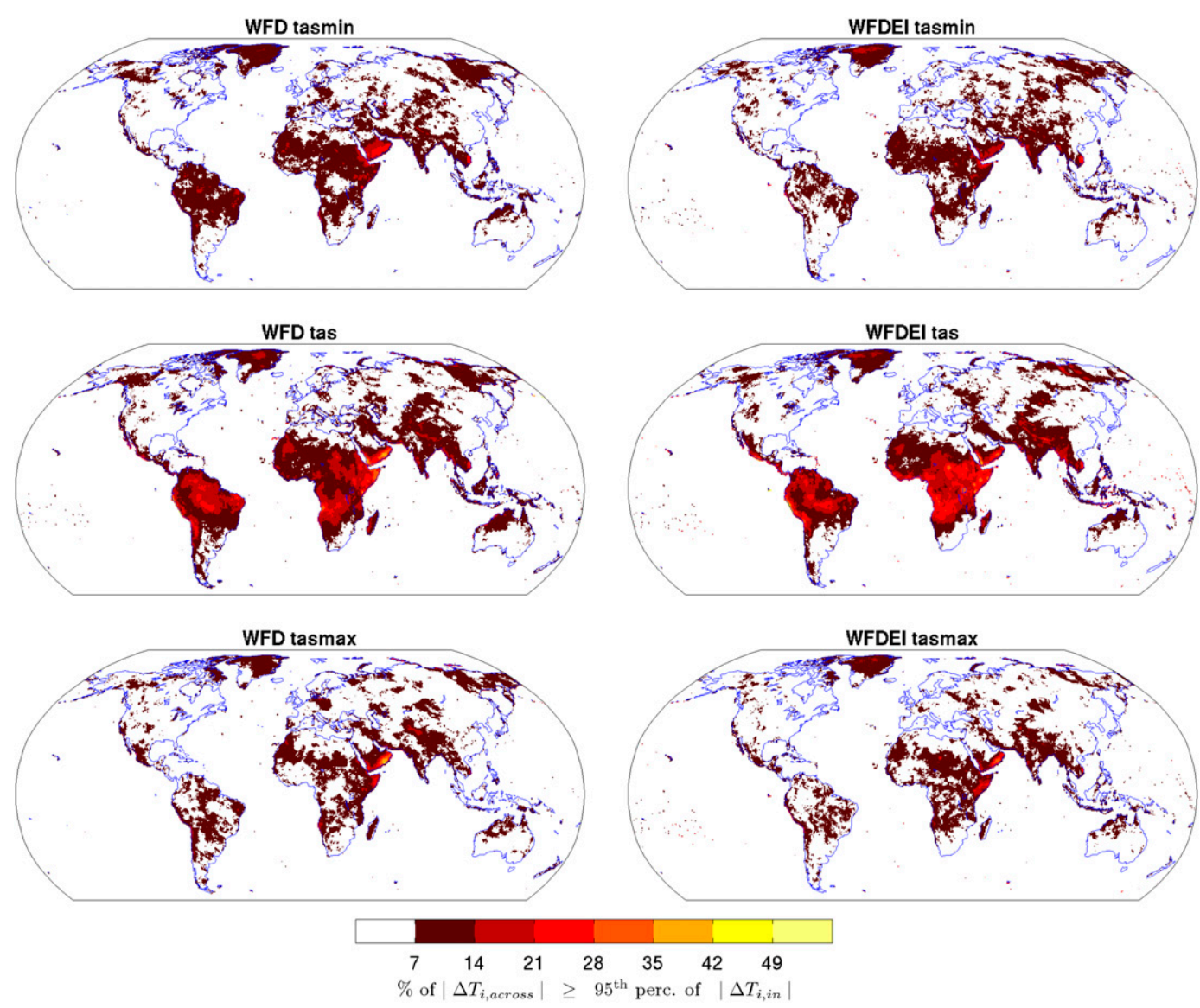

FIG. 3. Days (\%) with absolute across-months temperature fluctuations greater than the 0.95 quantile of absolute within-months fluctuations for (top) daily min temperature at surface, (middle) daily mean, and (bottom) daily max for (left) WFD and (right) WFDEI.

(negative) $t_{m}$ indicates a positive (negative) deviation of the climatological annual cycle caused by the adjustment scheme. The affected regions are identical to those mentioned before. However, implausible positive and negative across-months fluctuations are distributed differently across the year for different regions. For a given region, there are typically transitions with both large positive and large negative fluctuations. This is an indication that the seasonal cycle of the underlying reanalyses do not match the cycle of the CRU temperature series. Discontinuities are most severe in the transition seasons for the tropical regions, as well as the Northern Hemisphere subpolar to polar latitudes. While the direction of discontinuities is predominantly downward in spring and upward from summer to autumn over Greenland, Siberia exhibits an opposite behavior. The Arabian Peninsula shows downward (upward) jumps from late winter through early summer (late summer and autumn). North and southern Africa exhibit similar signals, and equatorial Africa exhibits an opposite behavior. These patterns extend more or less zonally, with
India and Southeast Asia behaving like equatorial Africa and opposite signs for South America and northern Australia. To allow a first assessment of whether these statistically significant implausible across-months fluctuations are relevant for further analyses to be built upon, Fig. 6 shows nonnormalized differences $\overline{\Delta T_{m, \text { across }}}-\overline{\Delta T_{m, \text { in }}}$ for mean temperature that are probably more intuitive than their normalized counterparts in Fig. 5. Discontinuities in the tropical regions that were found to be statistically highly significant in Fig. 5 are comparably small in absolute numbers. They hardly exceed a magnitude of $\pm 2^{\circ} \mathrm{C}$ and, hence, might be negligible in terms of potential impacts for applications such as hydrological modeling. However, results for the extratropics are completely different; magnitudes of across-months fluctuations are much larger here. In particular, those in (boreal) autumn, winter, and spring are striking, representing widespread sudden jumps of mean temperature on the order of $\pm 5^{\circ} \mathrm{C}$ and beyond. In North America, Greenland, and the frigid parts of Asia, discontinuities of a few degrees Celsius exists (e.g., up to 


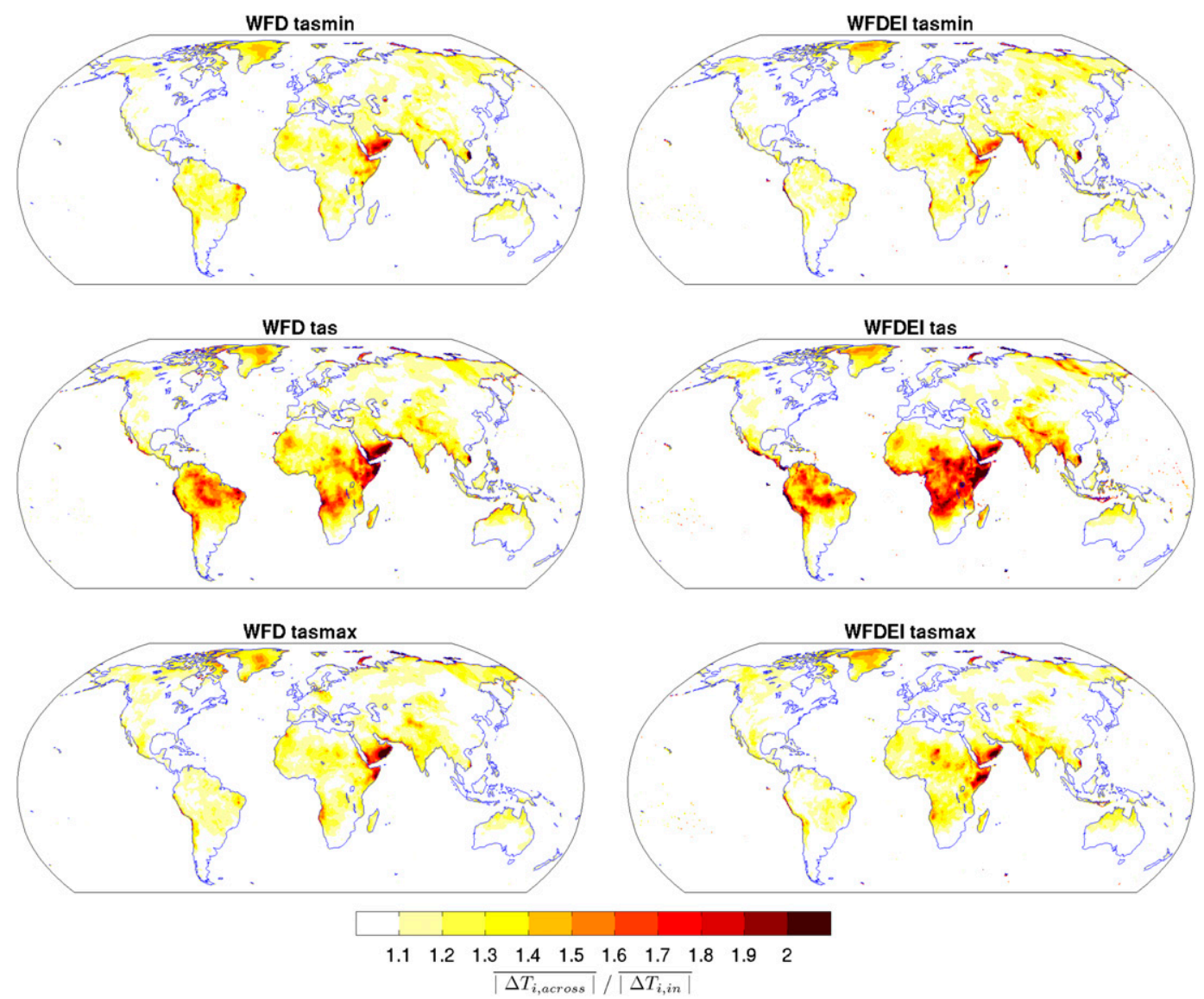

FIG. 4. Ratio of absolute across-months and within-months temperature fluctuations for (top) daily min temperature at surface, (middle) daily mean, and (bottom) daily max for (left) WFD and (right) WFDEI. Relative differences larger than 2 exist but are not depicted in separate color.

$7^{\circ} \mathrm{C}$ in Greenland for December-January), and their size is of the order of magnitude of the diurnal cycle (not shown). A few degrees Celsius difference in these regions are responsible for triggering snowmelt and are thus important for hydrological modeling. The corresponding figure for WFDEI (not shown) generally depicts very similar spatial structures and values.

\section{Conclusions}

The availability of consistent and homogeneous sets of global forcing data is of great importance for hydrological modeling and climate research. In particular, hydrological impact studies need a set of reference data with consistent temperature and precipitation. The WFD and WFDEI have been designed to meet these demands for the global land areas. However, in certain regions, implausible day-to-day differences in temperature across the boundaries of calendar months arise. These most likely result from a combination of the adjustment scheme used and a mismatch of the seasonal cycle of the two datasets under consideration. The adjustment scheme involves CRU monthly mean temperatures, and thus, adjustments change abruptly at the boundaries of calendar months if the seasonal cycles of CRU and ERA reanalyses differ in phase or amplitude. Hence, the introduction of discontinuities is not an effect of the adjustment scheme alone, nor of the CRU temperature dataset; problems occur when the seasonal cycles in the reanalysis and reference datasets differ in amplitude or phase. While this spurious effect of the adjustment scheme may not become evident in seasons and locations where normal within-months daily temperature fluctuation are comparably large, we found noticeable and potentially problematic differences in the tropics and frigid regions.

Daily mean temperature exhibits fluctuations between two consecutive months of about $150 \%$ or more of the size of the normal within-months daily temperature fluctuations for regions in South America and central Africa; for the Arabian Peninsula and Ethiopia, 

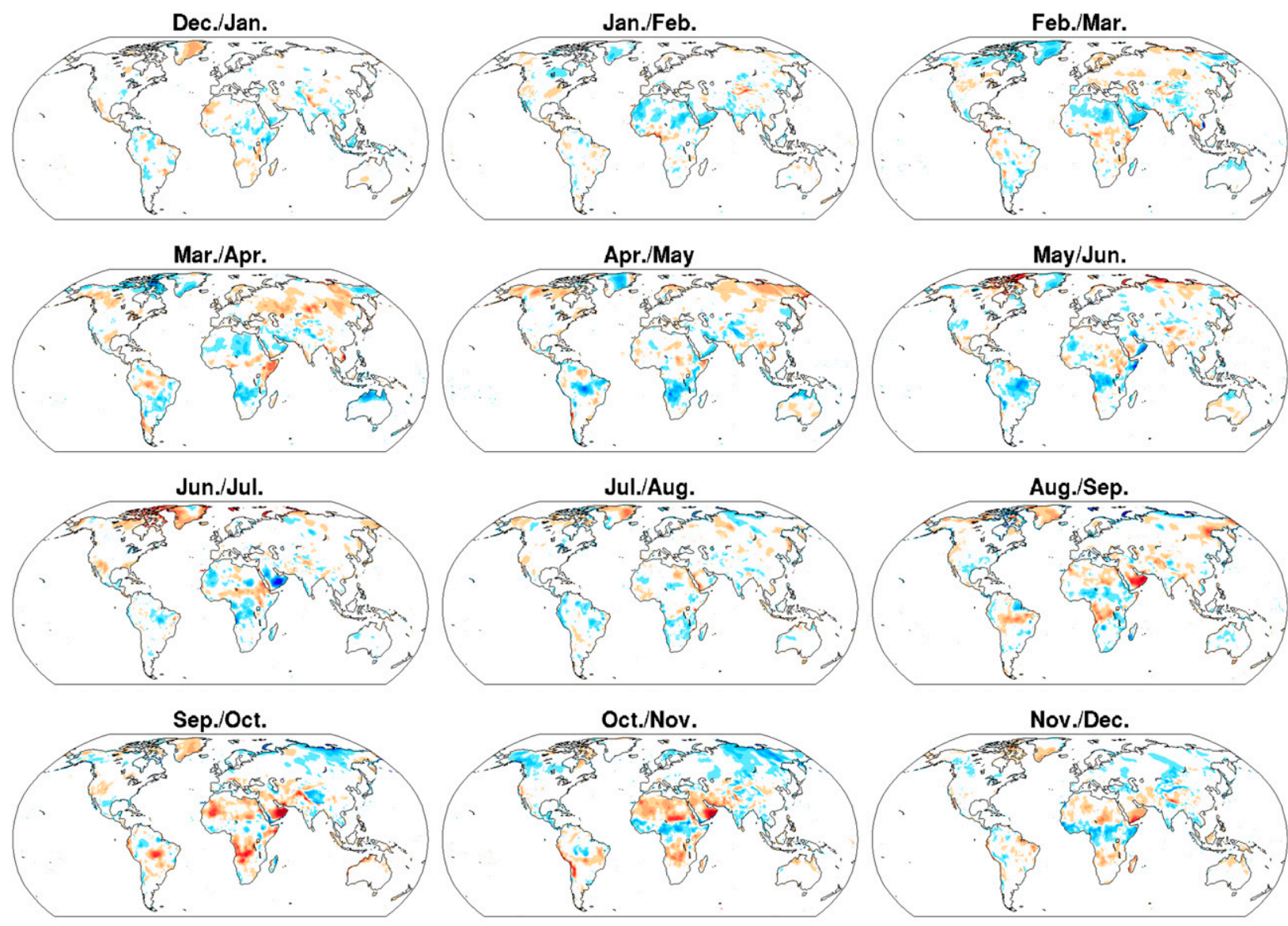

Oct./Nov.

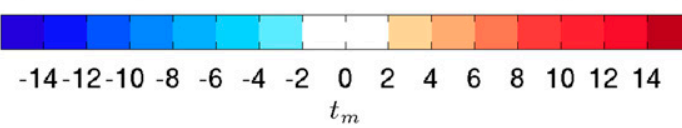

FIG. 5. Normalized mean differences between across-months and surrounding within-months daily mean temperature fluctuations [Eq. (3)] for WFD (e.g., top left shows mean difference from 31 Dec to 1 Jan related to the mean difference from 30 to 31 Dec and from 1 to 2 Jan).

twice the size is found. As extreme temperatures (tasmin, tasmax) exhibit larger day-to-day temperature fluctuations than daily mean temperatures (tas), the tolerance for inhomogeneous adjustments is larger for minimum and maximum daily temperatures. The discontinuities of a few degrees Celsius in the frigid regions can be decisive for triggering snowmelt and are thus relevant for hydrological modeling.

According to Weedon et al. (2011, Table 1), the adjustment scheme based on monthly values was applied to 2-m temperature, downward shortwave radiation, rainfall rate, and snowfall rate. Hence, these variables are potentially affected by discontinuities in the same way if similar mismatches between their seasonal cycles in the ECMWF reanalyses and the reference dataset exist. However, for variables such as precipitation, potential discontinuities are more difficult to detect as the day-to-day variability is a larger than for temperature. As monthly based adjustment schemes are also employed for other datasets, such as the Second Global Soil Wetness Project (GSWP2; Dirmeyer et al. 2002), the National Centers for Environmental PredictionNational Center for Atmospheric Research (NCEPNCAR) reanalysis corrected by CRU (NCC; Ngo-Duc et al. 2005), and the Princeton Global Forcing (PGF; Sheffield et al. 2006), these are potentially subject to similar issues.

Analysis of the individual months' transitions reveals the most severe discontinuities in the transition seasons, organized in approximately zonally symmetric patterns. Africa and the Arabian Peninsula exhibit the largest magnitudes of these discontinuities with downward jumps from boreal late winter to early summer and upward jumps in autumn.

A detailed assessment of related impacts on hydrological applications is beyond the scope of this study. 


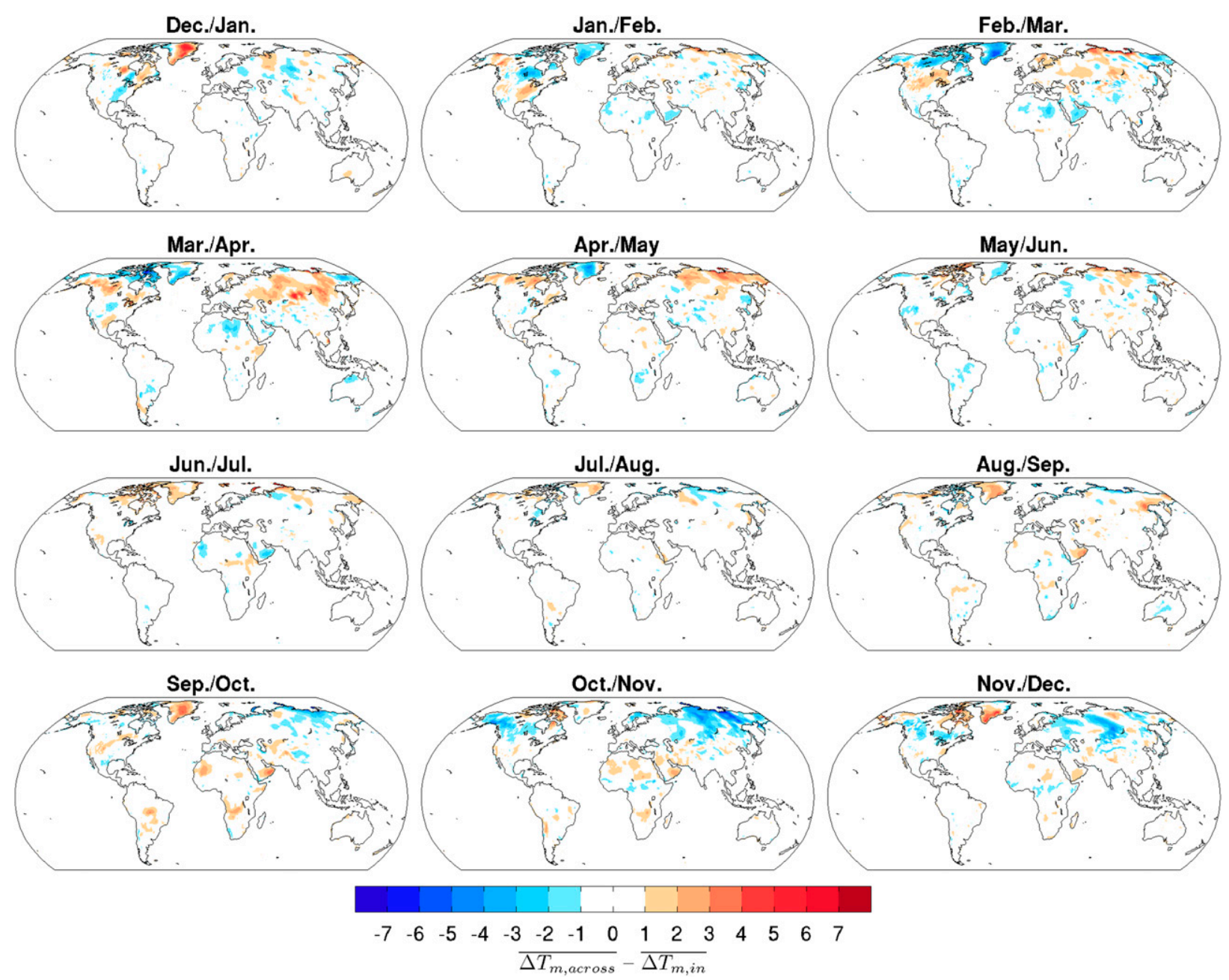

FIG. 6. Nonnormalized mean differences between across-months and surrounding within-months daily mean temperature fluctuations [numerator of Eq. (3)] (e.g., top left shows mean difference from 31 Dec to 1 Jan related to the mean difference from 30 to 31 Dec and from 1 to 2 Jan).

However, we assume that such impacts exist and imply significant consequences for hydrological applications. This is particularly reasonable when temperatures are close to $0^{\circ} \mathrm{C}$ and triggering of snowmelt comes into play. In conclusion, any application of the WFD or WFDEI in the mentioned regions should be aware of implausible temperature fluctuations across boundaries of calendar months.

Acknowledgments. Suggestions and comments from Graham Weedon and two anonymous reviewers helped to improve the manuscript; this is gratefully acknowledged! The authors thank Stefan Liersch and Stefan Hagemann for fruitful discussions, the Water and Global Change program (WATCH) for providing WFD, and the EU FP7 EMBRACE project for supporting the development of the WFDEI dataset.

\section{REFERENCES}

Dee, D. P., and Coauthors, 2011: The ERA-Interim reanalysis: Configuration and performance of the data assimilation system. Quart. J. Roy. Meteor. Soc., 137, 553-597, doi:10.1002/ qj.828.

Dirmeyer, P. A., X. Gao, and T. Oki, 2002: GSWP2: The Second Global Soil Wetness Project: Science and implementation plan. IGPO Publ. 37, International GEWEX Project Office, Silver Spring, MD, 64 pp. [Available online at www.iges.org/ gswp/GSWP2_SIplan.pdf.]

Gudmundsson, L., L. M. Tallaksen, K. Stahl, and A. K. Fleig, 2011: Low-frequency variability of European runoff. Hydrol. Earth Syst. Sci., 15, 2853-2869, doi:10.5194/hess-15-2853-2011.

Hagemann, S., C. Cui, J. O. Haerter, J. Heinke, D. Gerten, and C. Piani, 2011: Impact of a statistical bias correction on the projected hydrological changes obtained from three GCMs and two hydrology models. J. Hydrometeor., 12, 556-578, doi:10.1175/2011JHM1336.1.

Hempel, S., K. Frieler, L. Warszawski, J. Schewe, and F. Piontek, 2013: A trend-preserving bias correction-The 
ISI-MIP approach. Earth Syst. Dyn., 4, 219-236, doi:10.5194/ esd-4-219-2013.

Koch, H., S. Liersch, and F. F. Hattermann, 2013: Integrating water resources management in eco-hydrological modelling. Water Sci. Technol., 67, 1525-1533, doi:10.2166/wst.2013.022.

Mitchell, T. D., and P. D. Jones, 2005: An improved method of constructing a database of monthly climate observations and associated high-resolution grids. Int. J. Climatol., 25, 693-712, doi:10.1002/joc.1181.

New, M., M. Hulme, and P. Jones, 1999: Representing twentiethcentury space-time climate variability. Part I: Development of a 1961-90 mean monthly terrestrial climatology. J. Climate, 12, 829-856, doi:10.1175/1520-0442(1999)012<0829: RTCSTC $>2.0 . \mathrm{CO} ; 2$.

,-- , and - , 2000: Representing twentieth-century space-time climate variability. Part II: Development of 1901-96 monthly grids of terrestrial surface climate. J. Climate, 13, 2217-2238, doi:10.1175/1520-0442(2000)013<2217: RTCSTC $>2.0 . \mathrm{CO} ; 2$.

Ngo-Duc, T., J. Polcher, and K. Laval, 2005: A 53-year forcing data set for land surface models. J. Geophys. Res., 110, D06116, doi:10.1029/2004JD005434.

Piani, C., G. Weedon, M. Best, S. Gomes, P. Viterbo, S. Hagemann, and J. Haerter, 2010: Statistical bias correction of global simulated daily precipitation and temperature for the application of hydrological models. J. Hydrol., 395, 199-215, doi:10.1016/ j.jhydrol.2010.10.024.
Prudhomme, C., and Coauthors, 2014: Hydrological droughts in the 21st century, hotspots and uncertainties from a global multimodel ensemble experiment. Proc. Natl. Acad. Sci. USA, 111, 3262-3267, doi:10.1073/pnas.1222473110.

Sheffield, J., G. Goteti, and E. F. Wood, 2006: Development of a 50-year high-resolution global dataset of meteorological forcings for land surface modeling. J. Climate, 19, 3088-3111, doi:10.1175/JCLI3790.1.

Uppala, S. M., and Coauthors, 2005: The ERA-40 re-analysis. Quart. J. Roy. Meteor. Soc., 131, 2961-3012, doi:10.1256/ qj.04.176.

von Storch, H., and F. W. Zwiers, 1999: Statistical Analysis in Climate Research. Cambridge University Press, 483 pp.

Weedon, G. P., S. Gomes, P. Viterbo, H. Österle, J. C. Adam, N. Bellouin, O. Boucher, and M. Best, 2010: The WATCH Forcing Data 1958-2001: A meteorological forcing dataset for land surface- and hydrological-models. WATCH Tech. Rep. 22, $41 \mathrm{pp}$.

- and Coauthors, 2011: Creation of the WATCH forcing data and its use to assess global and regional reference crop evaporation over land during the twentieth century. J. Hydrometeor., 12, 823-848, doi:10.1175/2011JHM1369.1.

G. Balsamo, N. Bellouin, S. Gomes, M. J. Best, and P. Viterbo, 2014: The WFDEI meteorological forcing data set: WATCH Forcing Data methodology applied to ERAInterim reanalysis data. Water Resour. Res., 50, 7505-7514, doi:10.1002/2014WR015638. 